\title{
QUADRINHOS E TEOLOGIA: O DEMOLIDOR DA MARVEL COMO UM CAVALEIRO CRISTÃO
}

\section{Comics and Theology: Marvel's \\ Daredevil as a Christian Knight}

Bem-aventurados os que têm fome e sede de justiça, porque serão fartos.

(Mateus 5.6)

\section{Carlos Ribeiro Caldas Filho*}

Arquivo enviado em

$30 / 03 / 2019$

e aprovado em

05/07/2019

V. $9-$ N. $18-2019$

*Doutor em Ciências da Religião pela Universidade

Metodista de São Paulo (2000), pós-doutor em Teologia (PNPD-CAPES) pela Faculdade Jesuíta de Filosofia e Teologia.

\section{RESUMO}

A cultura pop (cinema e histórias em quadrinhos, HQ's) está presente no imaginário coletivo de bilhões de pessoas em todo o mundo. As HQ's, com suas narrativas de aventuras de super-heróis, constituem-se como uma das mais conhecidas expressões da cultura pop. Recentemente alguns têm sugerido a assim chamada teologia nerd, que estabelece a cultura pop como parceira de diálogo com a teologia. No entanto, muitas destas narrativas quase sempre são apresentadas em ambientes totalmente secularizados, sem referência ao transcendente. Uma exceção é o Demolidor, da Marvel, herói assumidamente cristão. O presente artigo pretende apresentar o Demolidor como a versão moderna do cavaleiro medieval, que entende o combate ao mal e à injustiça como uma maneira de serviço a Deus e ao próximo.

PALAVRAS-CHAVE: Cavalaria Virtudes - Histórias em quadrinhos - Teologia nerd - justiça 


\section{ABSTRACT}

Pop culture (movies and comic books) is present in the collective imaginary of billions of people around the world. Comics and their narratives of adventures of super heroes are one of the most well-known expressions of pop culture. Recently some have suggested the so called Nerd Theology that establishes pop culture as a partner of dialogue with theology. However, many of these narratives are presented in a totally secular environment, with no references to the transcendent. An exception to such a rule is Marvel's Daredevil, who is an admitted Christian hero. This article intends to present the Daredevil as a modern version of the medieval knight, who fights evil and injustice as a way of serving God and the neighbor.

KEY WORDS: Chivalry - Virtues - Comic Books - Nerd Theology Justice

\section{Introdução - A religião e o mundo dos super-heróis}

ste artigo pretende apresentar uma aproximação entre HQs e teologia. É uma tarefa difícil, porque em sua quase totalidade as narrativas dos super-heróis são seculares. Um exemplo: nas narrativas da DC as cidades fictícias Gotham City, Smallville ${ }^{1}$ e Metrópolis são apresentadas como não tendo nenhum templo cristão, o que é absolutamente inverossímil na realidade estadunidense que aquelas histórias ${ }^{2}$ pretendem representar. Este fato foi observado pelo filósofo estadunidense contemporâneo Tom Morris:

Não há muitas referências a Deus na linha básica das histórias de super-heróis. As atividades religiosas quase nunca aparecem nestas narrativas. Nós não vemos o Super-Homem sentado na igreja ou Bruce Wayne consultando uma Batbíblia para inspiração e orientação. O Quarteto Fantástico não possui momentos de oração

1. Nas animações do Superman exibidas na TV aberta brasileira nos anos de 1980 o nome da cidade de Smallville era traduzido (dublado) canhestramente como "Pequenópolis".

2. HQs são criações literárias ficcionais, logo, seria natural utilizar a palavras "estórias" para se referir a elas. Todavia, a Academia Brasileira de Letras não reconhece esta palavra. Por isso, neste texto optou-se pela palavra histórias. 
juntos para discernir a direção que seu trabalho deveria tomar ${ }^{3}$. O mundo dos super-heróis é de um modo geral, um lugar secular (MORRIS, 2009, p. 55).

A observação de Morris poderia ser matizada se levar-se em consideração que alguns super-heróis têm origem mitológica, ou seja, origens ligadas, de alguma maneira, ao mundo da religião em sentido bastante amplo: Thor e Hércules, entidades respectivamente das mitologias nórdica e grega, foram transformados por Stan Lee em super-heróis da Marvel. A mesma Marvel tem o Doutor Estranho, o "Mago Supremo" da Terra, que domina artes mágicas e luta contra entidades astrais malignas ${ }^{4}$. A Mulher Maravilha, da DC, é uma semideusa, pois é filha de Hipólita, uma rainha das amazonas, e Zeus, a figura principal do panteão grego. Shazam, também da DC, tem seus poderes extraídos, pela via da magia, de entidades ligadas ao imaginário judaico-cristão e à mitologia grega $a^{5}$. Mais recentemente (2011) a DC lançou a "Liga da Justiça Sombria" (Justice League Dark), que tem entre seus integrantes personagens que são, no mínimo, curiosos, como o mago e exorcista John Constantine, a mágica Zatanna Zatara (filha do também mágico Giovanni Zatara), e Zauriel, um anjo guardião do Céu que se auto exilou para a Terra ${ }^{6}$, e Etrigan, curioso ser que,

3. Ao mencionar "momentos de oração juntos" Morris faz referência ao chamado "culto doméstico", prática devocional familiar de leitura bíblica e oração muito popular na cultura evangélica em geral.

4. Nas narrativas do Doutor Estranho não há nenhuma religião específica, mas suas histórias são apresentadas com uma estética que sugere uma mescla de hinduísmo com budismo tibetano. Para uma apresentação um pouco mais detalhada do Doutor Estranho consultar GUERRIERO, STERN (2019, 205, 207).

5. O nome SHAZAM é um anagrama: Salomão (sabedoria), Hércules (força sobre-humana), Atlas (resistência e invulnerabilidade), Zeus (poder, incluindo a capacidade de comandar raios e trovões), Aquiles (coragem) e Mercúrio (velocidade, incluindo a capacidade de voar).

6. Zauriel não aparece muito nas histórias da DC, mas é um personagem interessante: ele servia à Presença em Pax Dei, mas se exila na Terra. "Presença" é o nome de Deus no universo DC, e Pax Dei - literalmente, "Paz de Deus" - é o nome da cidade onde está a Presença governando todo o multiverso. 
mesmo sendo um demônio infernal, se aliou às forças do bem. No universo da DC, a Liga da Justiça Sombria combate ameaças espirituais malignas do plano astral que não poderiam ser enfrentadas por super heróis "convencionais", como o Batman e o Superman.

Ainda mais recentemente (2013) a Marvel lança a personagem Kamala Khan, uma norte-americana muçulmana, filha de imigrantes paquistaneses. Ela é apresentada como adotando uma versão mais liberal do islamismo, e algumas vezes entra em conflito com seu irmão, que tem tendência fundamentalista.

Encontram-se eventualmente também referências em várias HQs ao fato de Clark Kent, o Superman ser criado em uma igreja metodista no Kansas, a Steve Rogers, o Capitão América, e Peter Parker, o Homem Aranha, serem protestantes (não se mencionam especificamente quais são as igrejas das quais eles são membros), a Natasha Romanoff, a Viúva Negra da Marvel, ser uma ortodoxa russa não praticante, e ao judaísmo do Coisa, do Quarteto Fantástico. Aliás, este personagem é bastante interessante, por ser o único assumida e declaradamente judeu, a tradição religiosa de seus criadores, Stan Lee e Jack Kirby, ambos igualmente judeus. Nas HQs o nome do Coisa é Benjamin Jacob Grimm, nome tipicamente judeu. Personagem claramente inspirado na lenda judaica do Golem de Praga ${ }^{7}$, o Coisa é um gigante de pedra que em histórias mais recentes é apresentado discutindo abertamente temas de sua crença religiosa. Em uma história famosa, apresenta-se o

7. A lenda do Golem de Praga é uma espécie de "Frankenstein antes de Mary Shelley": é a história de um ser artificial criado pelo rabino Judah Loew ben Bezalel no bairro judeu da Praga do século XVI, que adquiriu vida por meio de encantamentos. O Golem deveria proteger o bairro judeu de ataques antissemitas. Dois escritores judeus contemplados com o Prêmio Nobel produziram versões da lenda do Golem, a saber, Elie Wiesel (19282016), Nobel da Paz, e Isaac Bashevis Singer (1902-1991), Nobel de Literatura. Para detalhes, consultar as referências, ao final deste artigo. 
Coisa (re)fazendo sua cerimônia de Bar Mitzvah, o conhecido rito de passagem judaico, porque já havia treze anos desde o acidente que o fez se transformar no gigante de pedra.

Mas, a despeito desta breve problematização da observação de Morris, em linhas gerais ele está correto em sua observação: o mundo dos super-heróis é secularizado. Uma exceção quanto a isto é exatamente o Demolidor, que será apresentado na sequência deste artigo.

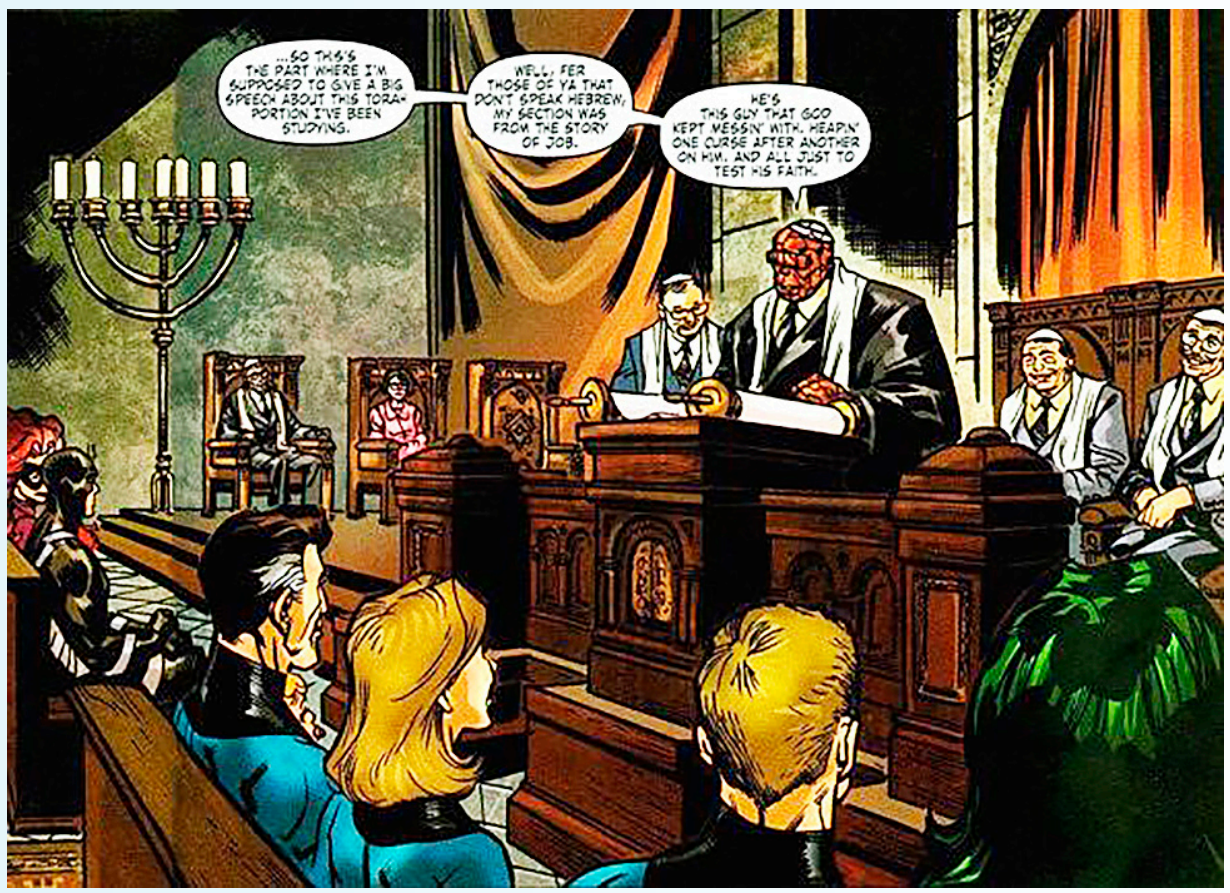

Figura I: 0 segundo Bar Mitzvah do Coisa

\section{Quem é o Demolidor}

Todavia, como que "nadando contra a correnteza" que é a tendência secularizante que domina o mundo das narrativas de 
super-heróis, o Demolidor da Marvel, que se constitui no objeto do presente artigo, é apresentado como um cristão católico praticante $^{8}$. De fato, o catolicismo do Demolidor é peça fundamental para que se entenda o personagem. Quanto a isto, também é preciso observar que a apresentação do Demolidor como personagem assumidamente católico só aparece a partir da recriação do herói feita por Frank Miller, em 1986. Por oportuno, registre-se que Frank Miller tornou-se mundialmente conhecido pelos consumidores da cultura pop pelo seu trabalho de recriar não apenas o Demolidor, mas também o Batman, da DC, um dos mais icônicos personagens de todos os multiversos e pluriversos nerd. O Cavaleiro das Trevas, de Frank Miller, o reboot que fez do Batman, tornou-se referência definitiva na história do "Homem Morcego", assim como A queda de Murdock, do mesmo autor, se tornou na história do Demolidor.

Antes de prosseguir, há um ponto que precisa ser destacado: o título original de A queda de Murdock é Born Again, literalmente, "nascido de novo". Esta é uma expressão do Novo Testamento em inglês, especificamente, parte do diálogo de Jesus com Nicodemos, registrado no Evangelho de João $(3.3,7)$. O público leitor no contexto estadunidense provavelmente perceberia com maior facilidade a referência bíblica do título. No Brasil, optou-se por uma tradução interpretativa, que foge por completo ao sentido do título original, muito embora seja fiel ao conteúdo propriamente da narrativa. Em A queda de Murdock é introduzido o elemento

8. No universo Marvel o único outro super-herói que também é católico praticante é Kurt Wagner, o Noturno, um dos mutantes integrantes dos X-Men. Alemão radicado nos Estados Unidos, Noturno, por conta de sua mutação, tem a aparência de um demônio conforme o imaginário popular medieval. 
do catolicismo na narrativa do herói ${ }^{9}$. Até então, o Demolidor era tão secular quanto todos os demais heróis da Marvel. A respeito da recriação do Demolidor feita por Miller o crítico de quadrinhos brasileiro Leonardo Porto Passos afirmou: "Outro elemento bastante presente é a religiosidade, que Miller explorou eficazmente para dar profundidade e sentido à vida de Murdock como herói mascarado e também como órfão abandonado por uma mãe que virou freira" (PASSOS, 2014). Serão apresentadas a seguir informações básicas sobre o personagem Demolidor (Daredevil), pensando nos leitores que não têm familiaridade com a mitologia do herói (por certo haverá entre os leitores deste artigo quem já o conheça e goste de ler as narrativas de suas aventuras) ${ }^{10}$.

O herói foi criado por Stan Lee (1922-2018), o "pai” de quase todos os heróis da Marvel) e Jack Kirby (1917-1994) ${ }^{11}$, que trabalhou para a Marvel e para a DC), tendo como desenhista Bill Everett (1917-1973). A primeira edição da revista do Daredevil nos Estados Unidos foi publicada em abril de 1964. Nas primeiras edições desta revista o Demolidor era apresentado usando um uniforme vermelho e amarelo. Posteriormente apenas sua concepção mudou para o atual uniforme todo vermelho. Os pequenos chifres em sua máscara, que o fazem parecido com uma figura de diabo conforme o imaginário ocidental, são para assustar os criminosos.

9. A edição mais recente de A queda de Murdock no Brasil é de 2013.

10. Por oportuno, é importante ressaltar que este artigo não tratará da recente série televisiva (duas temporadas até o momento) do Demolidor, uma parceria da Marvel, que detém os direitos do personagem, com o canal de streaming Netflix. A narrativa de origem do Demolidor nesta série televisiva é bastante fiel ao registro da biografia ficcional do personagem nas HQ's, conforme a já mencionada recriação do personagem conduzida por Frank Miller.

11. Para uma biografia de Jack Kirby, consultar GUEDES (2017). 


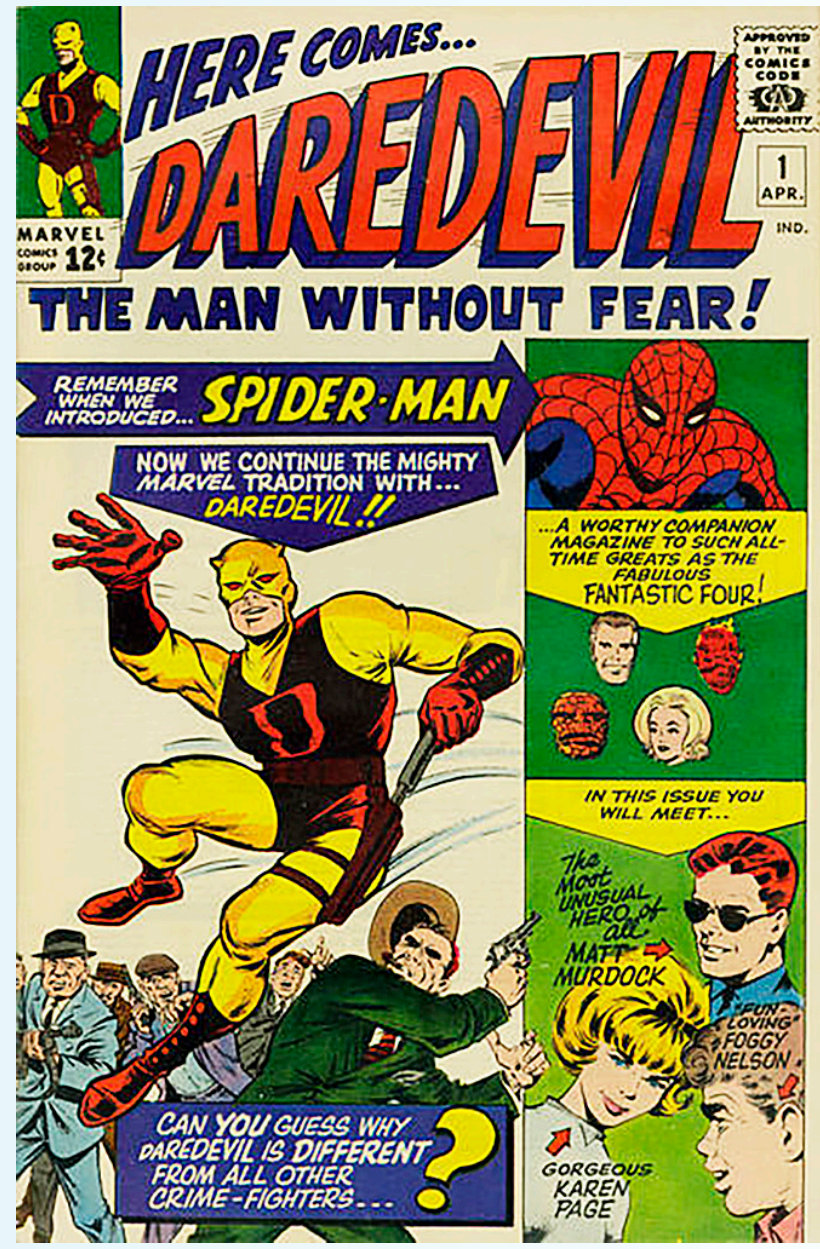

Figura 2: capa da primeira edição nos Estados Unidos de Daredevil ${ }^{12}$

Em suas histórias o Demolidor é chamado também de "O homem sem medo" e de "O demônio de Hell's Kitchen"13. Matt foi

12. Daredevil. Extraído de Grand Comics Database (GCD). Disponível em < https://www. comics.org/issue/18338/> Acesso: 27 nov 2017. Observa-se nesta época, nos anos de 1960, que não apenas o Daredevil, mas todos os super heróis em geral, eram apresentados de uma maneira que hoje é considerada ingênua. A mencionada reconfiguração do personagem feita por Frank Miller apresenta uma narrativa sombria, realista, tanto quanto possível para o gênero de super aventuras de super heróis, não escondendo de modo algum as limitações, em todos os sentidos, de Matt Murdock.

13. Hell's Kitchen (“Cozinha do inferno") é um bairro tradicional de imigrantes irlandeses pobres na Ilha de Manhattan em Nova lorque. 
criado apenas pelo pai, Jonathan (“Jack”) Murdock, pois a mãe abandonou o lar. Seu pai insiste com ele para que estude, e se forme médico ou advogado, e assim não tenha que passar pelas dificuldades financeiras de um boxeador já velho para a profissão, e com problemas de dependência de álcool. Jack, que já teve seus dias de glória, por conta de sua tenacidade no ringue é conhecido como Battlin ("Batalhador"). Quando criança, o menino Matt em um impulso salva um homem de ser atropelado por um caminhão que transportava produtos radioativos. O caminhão capota, um dos latões com material radioativo cai na rua, e se rompe com a queda. O material espirra no rosto do menino, atingindo seus olhos. Ele fica cego em consequência do acidente, mas em compensação, os outro quatro sentidos ficam super desenvolvidos, mais que os de qualquer outra pessoa. Matt adquire também um sentido de radar, que virtualmente compensa a falta de visão. Pouco depois de sua saída do hospital o menino Matt é encontrado por um homem misterioso, igualmente cego, chamado apenas de Stick ${ }^{14}$, e que o ensinará a usar suas recentemente adquiridas habilidades e, mais ainda, o ensinará diferentes modalidades de artes marciais. Stick se revelará um mentor severo, que sempre exige mais e mais de seu discípulo, para que este alcance o máximo de destreza em combate que um lutador pode alcançar.

O jovem Matt se tornará aluno de Direito na Universidade Columbia, atendendo ao desejo de seu pai. Lá, conhecerá Franklin "Foggy" 15 Nelson, que virá a ser seu melhor amigo. Como a maioria dos heróis, ele também tem uma identidade dupla e, por isso

\footnotetext{
14. O nome propriamente do enigmático mestre de Matt Murdock nunca foi citado em nenhuma HQ. O apelido de Stick ("vareta", "graveto" ou "bastão") Ihe foi dado por ser descrito fisicamente como sendo muito magro.

15. A palavra foggy significa literalmente "nebuloso", e pode ter o sentido de "confuso" ou "atrapalhado", o que parece se aplicar bem ao colega e amigo de Matt Murdock.
} 
mesmo, vive uma vida dupla: sua identidade conhecida é a de Matthew Michael Murdock (ou simplesmente, Matt Murdock), um advogado brilhante. A vida dupla de Matt é a de um advogado, defensor de causas de pessoas pobres durante o dia, e de combatente do crime durante a noite.

Resumindo: o Demolidor tornou-se um dos heróis mais complexos e mais amados de todo o universo Marvel. E como se verá na sequência deste artigo, desde a reconfiguração do herói feita por Frank Miller (e seguida na década de 1990 pelo roteirista Kevin Smith) a grande força motivadora de Matt Murdock/Demolidor é sua fé cristã. Miller não apenas introduziu o elemento da fé cristã na narrativa do Demolidor, como também conseguiu "transportá-lo", por assim dizer, do segundo escalão da Marvel para uma posição de destaque igual a dos super-heróis do primeiro escalão, como o Homem Aranha, o Wolverine e o Capitão América.

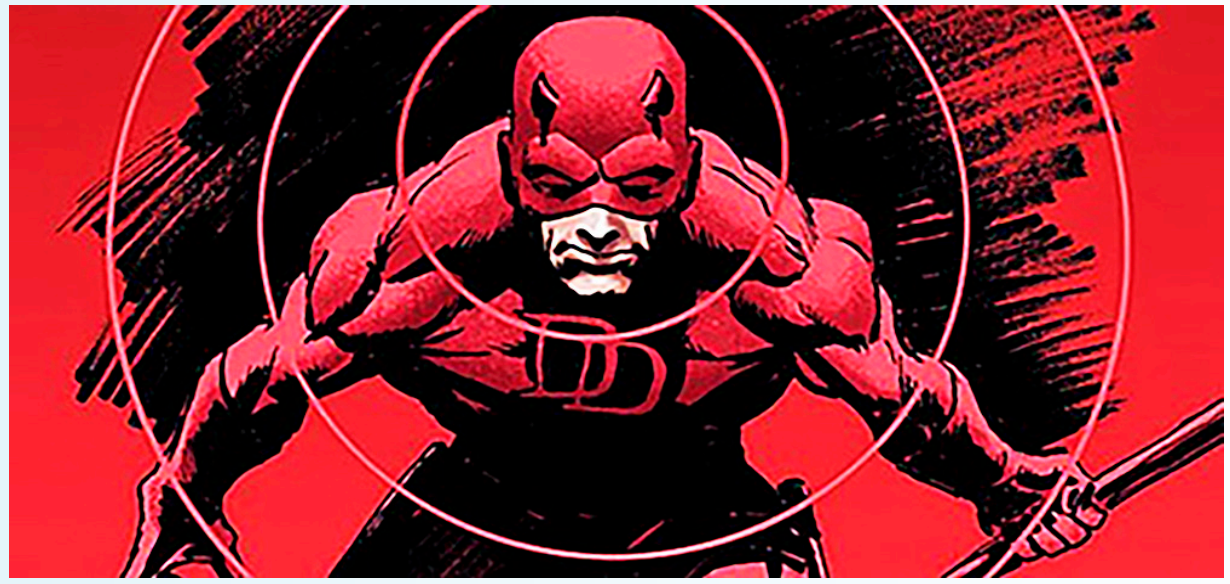

Figura 3: a representação clássica do Demolidor, com uniforme vermelho e sua arma, um bastão retrátil. Os círculos concêntricos ao redor de sua cabeça representam seu sentido de radar, que compensa sua falta de visãa ${ }^{16}$.

16. Extraído de http://www.marvel616.com/2015/01/charlie-cox-fala-sobre-o-uniforme-do.html 


\section{0 cavaleiro medieval como um servo de Deus}

Este artigo pretende demonstrar que o personagem Demolidor é a representação atual de um cavaleiro medieval, o herói cristão por excelência. Para tanto, recorrer-se-á a uma hipótese defendida pelo filósofo estadunidense Tom Morris (2009, 55-69), qual seja, que a motivação do Demolidor em suas histórias é a de, com suas habilidades, servir a Deus e ao próximo. Recorrer-se-á também a fontes que apresentem como na Idade Média a instituição da cavalaria era entendida como algo religioso, uma instituição sagrada. Estas fontes serão primariamente da historiografia francesa, que muito tem se dedicado ao estudo do tema. Um destes historiadores é Michel Pastoreau, pesquisador do tema que, a respeito, observou sobre questões econômicas e sociais envolvendo a origem da instituição da cavalaria:

A cavalaria é uma instituição que se implantou no sistema feudal por volta do ano 1000. No sentido estrito, cavaleiro é todo homem de armas que se submeteu aos ritos de uma cerimônia de iniciação específica: a sagração do cavaleiro. Contudo, não basta ter sido ordenado; deve-se também obedecer a certas regras e, sobretudo seguir um modo de vida particular. Os cavaleiros não formam uma classe jurídica, mas uma categoria social que reúne especialistas em combate de cavalaria - o único eficaz até o final século XIII - e que dispõe dos meios de levar essa existência à parte, que é a vida de cavaleiro. Teoricamente, todo homem batizado tem acesso à cavalaria: cada cavaleiro pode tornar cavaleiro aquele que ele julgar digno de sê-lo, não importa a origem ou a condição social. As canções de gesta oferecem muitos exemplos de plebeus (camponeses, lenhadores, guardadores de porcos, comerciantes, jograis, cozinheiros, porteiros, etc que se sagraram cavaleiros em recompensa por serviços prestados ao herói (PASTOREAU, 1989, p. 42).

Todavia, com o tempo, apenas alguns na sociedade apresentavam efetivamente condições de se tornarem cavaleiros: 
Mas a realidade é outra. A partir da metade do século XII, os cavaleiros tendem a ser recrutados quase exclusivamente entre os filhos de cavaleiros, formando uma casta hereditária. Se não chegam a desaparecer de vez, a sagração de plebeus torna-se um fato excepcional ${ }^{17}$. Por dois motivos: o primeiro reside no processo de cooptação que favorece inevitavelmente o controle de uma classe, a aristocracia da terra, sobre uma instituição que não é regida por nenhuma norma de direito; o segundo - talvez mais importante - deve-se a imperativos socioeconômicos: o cavalo, o equipamento militar, a cerimônia e as festas de sagração exigem altas somas. A própria existência do cavaleiro, feita de prazeres e ociosidade, pressupõe uma certa (sic) riqueza, que naquela época provinha apenas da terra. Ser cavaleiro, com efeito, significa glória e honra; portanto, é preciso viver, seja da generosidade de um rico e poderoso senhor (um favor que ainda pode ser obtido facilmente no começo do século XII, mas que se torna mais difícil cem anos depois), seja dos rendimentos de um patrimônio (PASTOREAU, 1989, p. 43).

Quanto a isto, Georges Duby acrescenta:

No século XIII, a cavalaria forma, em todo o Ocidente, um corpo muito bem delimitado, verdadeiramente colocado no centro do edifício social. Adoptou (sic) a superioridade e a excelência outrora ligadas à noção de nobreza (DUBY, 1989, p. 31).

Jean FLORI resume esta questão social da cavalaria em uma frase de poucas palavras: "Na cavalaria não entra quem quer!" (FLORI, 2002, p. 185, 190).

O cavaleiro era o miles (palavra latina na raiz de militar, militância, milícia) (DUBY, 1989, p. 32). A literatura francesa chamará o miles de chevalier, literalmente, "cavaleiro" (FLORI, 2002, p. 6). A cavalaria ocupava lugar importante na estrutura social medieval.

17. Este é o tema do filme A Knight's Tale, ("Coração de cavaleiro" no Brasil), de 2001, do diretor Brian Helgeland: a história de um jovem pobre, que sonha em ser sagrado cavaleiro. O roteiro é uma adaptação de um dos Canterbury Tales ("Contos da Cantuária") de Geoffrey Chaucer, escritor inglês do século XIV que, a propósito, como forma de metalinguagem, aparece na adaptação fílmica como um de seus personagens. 
Georges Duby recupera documentos importantes neste sentido:

No seu tratado De imagine mundi, Honorius Augustodunensis explica que o gênero humano foi, depois do dilúvio, repartido em três categorias sociais, os liberi, filhos de Sem, os milites, filhos de Jafet (sic), e os servi, filhos de Cham (sic). Dele faz eco, alguns decênios mais tarde, essa crônica alsaciana de 1163 evocada por Karl Bosl, onde se pode ler que Júlio Cesar, depois de ter conquistado as Gálias, estabeleceu os senadores como príncipes, os simples cidadãos romanos como milites, embora depois disso os cavaleiros, superiores aos rústicos mas inferiores aos nobres, cooperassem na manutenção da paz (DUBY, 1989, p. 37).

Não há como não perceber o uso do texto bíblico para legitimar uma ideologia de dominação de não europeus, visto que tradicionalmente o texto de Gênesis que fala dos três filhos de Noé tem sido interpretado como encontrando neles os antepassados dos três povos da bacia do Mediterrâneo: os filhos de Sem seriam os judeus e árabes, os de Jafé, os europeus, e os de Cam, os africanos. Os textos recuperados por Duby são da época das Cruzadas, e, não por mera coincidência, são exatamente os europeus, que se entendiam como descendentes de Jafé, que são apresentados como milites.

A cavalaria era vista como uma maneira de servir a Deus. Caberá ao chevalier "a proteção das igrejas, dos fracos e dos desarmados (inermes)" (FLORI, 2002, p. 186). Quanto a isto, Duby acrescenta:

Desde que os homens da Igreja se puseram a reflectir (sic) sobre a vocação respectiva dos diferentes corpos da sociedade humana e nas diversas missões que Deus confere aos homens quando os coloca nesta ou naquela condição terrena, depressa descobriram que havia na realidade do seu tempo duas maneiras diferentes de militare, de servir a Deus e de cooperar para o bem público: pelas armas e pela oração. Numa carta do papa 
Zacarias a Pepino, datada de 747, o balanço da frase opõe aos príncipes os bispos, aos saeculares homines os padres, aos bellatores os Dei servi, que cooperam, cada qual segundo a sua vocação, na defesa do país; na pena de Agobard, em 833, a oposição é estabelecida entre duas ordines, "militar" e eclesiástica, isto é, entre a saecularis militia e o sacrum ministerium (DUBY, 1989, p. 42, ênfases do autor).

A exposição feita por Duby deixa claro como se pensava na Idade Média na cavalaria como sendo uma possibilidade de serviço cristão: o cavaleiro, homem de ação, servia a Deus e ao próximo como o clérigo, homem de oração. O cavaleiro tinha a virtude perfeita, uma virtude dupla, no sentido pragmático, porque sabia cavalgar, empunhar armas e lutar, e no moral, porque deveria usar sua habilidade não como maneira de satisfazer sua vaidade, mas para defender os que não podiam fazê-lo. O cavaleiro deveria ser um instrumento de justiça no mundo e, como tal, estaria servindo a Deus. Este aspecto é destacado com clareza pelo medievalista brasileiro José Roberto Mello:

Aparecia pois a ordem da cavalaria para a defesa da sociedade. $\mathrm{O}$ acesso a ela exigia coragem para assumir os pesados deveres então impostos. Estes adivinham de qualidades éticas encontradas no coração do homem, a saber: coragem, fortaleza, lealdade, piedade, senso de justiça e prodigalidade (no bom sentido, evidentemente, a largesce, oposta à avareza) [...] O cavaleiro era, destarte, um especialista das armas e devia emprega-las bem, na defesa dos fracos, das viúvas, dos injustiçados e da Santa igreja (MELLO, 1992, p. 88-89).

Se havia virtudes que o cavaleiro, por definição, deveria ter, havia de igual maneira defeitos que deveria evitar. Dentre estas as piores seriam a deslealdade e a covardia. "Traidor (félon, traître) era o pior designativo que alguém poderia merecer" (MELLO, 1992, p. 89). O cavaleiro não poderia ser covarde. Não por simples aca- 
so ou mera coincidência, o Demolidor será chamado de "O homem sem medo": a palavra no original em inglês que dá nome ao herói é Daredevil, que traduzida ao pé da letra seria "diabo atrevido", significa literalmente "ousado", "destemido". Usa-se daredevil para se referir, por exemplo, a um piloto de provas, a um trapezista ou equilibrista de circo, ou a qualquer profissão cujo exercício demande coragem.

Fato é que a cavalaria se torna cada vez mais uma instituição cristã: "Aos poucos, a cavalaria foi sendo cristianizada, um cerimonial litúrgico organizado para o ingresso no seu seio e regras de conduta estipuladas para os participantes" (MELLO, 1992, p. 90). O mesmo Mello traz observações importantes a respeito. A citação a seguir é um tanto longa, mas merece ser reproduzida:

Com o advento das cruzadas, a tarefa magna dos cavaleiros transformou-se no combate aos infiéis - é o tema dominante no primeiro ciclo da literatura francesa, o das canções de gesta. O pensamento de S. Bernardo de Claraval idealizou, em meados do século XII, a militia Christi, que acabou se concretizando nas ordens militares com campo de ação na Terra Santa, a dos Cavaleiros do Hospital de S. João de Jerusalém, ou hospitalários, e a dos Cavaleiros do Templo, ou templários, sem falar em outras que continuaram surgindo na Europa até o final da Idade Média. Unia-se, assim, o ideal laico, cavalheiresco, ao ideal religioso, monacal, criando-se o monge-cavaleiro. Pois bem, esse ideal é retomado mais ou menos disfarçadamente no ciclo Vulgata do Graal, no momento mesmo em que aquelas duas ordens alcançavam o apogeu no orbe cristão. Através da substituição de personagens, topamos aí com um gradual aperfeiçoamento da figura cavalheiresca em direção ao monge-cavaleiro, caracterizado por todas as qualidades inerentes ao herói laico, coroado pela humildade e pela castidade. Na Queste del Saint Graal ${ }^{18}$ esse ideal é levado ao ponto de o autor distinguir dois tipos de cavalaria, a terrena, dos homens, e a celestial, dos anjos e dos santos; e, paralelamente, duas ordens de

18. "Busca do Santo Graal". 
aventuras, as materiais e as espirituais. Estas últimas consistiam na provação e na descoberta dos elementos simbólicos que conduziriam à maior aproximação com a divindade, estando pois reservadas aos aspirantes à milícia celestial. Ao aperfeiçoamento das aventuras correspondem também modificações importantes nos método de completa-las e, aqui, o autor introduz timidamente a condenação da brutalidade dos costumes cavaleirescos, sobretudos da matança desnecessária de cristãos. Galaad é assim o "cavaleiro branco", capaz de lutar sem provocar a morte do adversário (MELLO, 1992, p. 91-92).

Esta última observação apresentada por Mello é particularmente interessante para os propósitos do presente artigo, porque o Demolidor é exatamente o combatente que não mata. Sendo assim, ele é um "cavaleiro branco", como Galaad (ou Galahad) que se veste de vermelho.

O já citado Pastoreau acrescenta comentários importantes quanto ao aspecto sagrado da cavalaria medieval, que tinha uma cerimônia de ordenação, a mesma palavra aplicada para quem se inicia na vida religiosa. Pastoreau assim descreve a cerimônia de ordenação de um cavaleiro medieval:

A cerimônia propriamente desenrola-se segunda uma ordem sacralizada. Ela se inicia pela bênção das armas, que o padrinho entrega a seguir ao afilhado: primeiro a espada e as esporas, a seguir a cota de malha e o elmo, por fim a lança e o escudo. $O$ escudeiro veste a indumentária, recita algumas preces e pronuncia um juramento, pelo qual se compromete a respeitar os costumes e as obrigações da cavalaria. A cerimônia termina com a palmada no ombro, gesto simbólico, cuja origem e significado permanecem controvertidos e de variadas formas: mais frequentemente, o oficiante, de pé, desfere sobre o ombro ou a nuca do futuro cavaleiro, que se encontra ajoelhado diante dele, um forte golpe com a palma da mão. Em certos condados da Inglaterra e algumas regiões da França ocidental, esse gesto se reduz a um simples abraço ou um vigoroso aperto de mão. No século XIV, esse ritual não se fará mais com 
a mão, mas com a lâmina da espada, e será acompanhada da fórmula: "Em nome de Deus, de São Miguel e de São Jorge, eu te declaro cavaleiro"19 (PASTOREAU, 1989, p. 45).

FLORI acrescenta um detalhe: antes do início da cerimônia de ordenação do cavaleiro havia um banho ritual, como que uma cópia do batismo cristão: "O banho que precede a cerimônia, de origem utilitária e até mesmo profana, assume simbolismo cristão envolvendo o tema da pureza" (FLORI, 2002, p. 194). O aspecto sagrado da cavalaria está explícito na cerimônia de ordenação, ritual religioso por definição. A ordenação, seja de um padre, seja de um cavaleiro, pública e oficialmente inicia um homem de bem no serviço a Deus, seja pelo serviço eclesiástico, seja pelo serviço das armas.

Exatamente por isso o cavaleiro não pode ser apenas alguém habilidoso em combate singular. Para o cavaleiro medieval cristão, tão importante quanto a destreza em combate é a exigência ética ${ }^{20}$. A questão do código de conduta elevada que se espera de um cavaleiro é apresentada no conto de Percival, reproduzido por Pastoreau, no qual Gornemant de Goort ${ }^{21}$ ensina ao seu jovem discípulo:

19. Observem-se a brevidade da fórmula litúrgica de ordenação, e a invocação tríplice, a Deus, que no Antigo Testamento é apresentado como "homem de guerra" (Êx 15.3), a Miguel, príncipe dos arcanjos celestiais, aquele que derrotou o próprio diabo (cf. Ap 12.79), e a São Jorge, santo guerreiro muito popular nas tradições ocidental e oriental, aquele que derrotou um dragão, tradicional símbolo do mal no imaginário cristão.

20. O alto ideal ético do cavaleiro medieval cristão faz lembrar o Bushido ("caminho do guerreiro"), o equivalente na cultura japonesa para o samurai. Este não pode ser apenas habilidoso com a espada, a luta corporal, a equitação e o arco e flecha. Antes, também precisa seguir um código elevado de conduta marcado pela honra. Um samurai sem honra é uma contradição de termos.

21. Gornemant de Goort é o mentor de Percival no romance medieval Perceval ou Le Conte du Graal ("Percival, ou o Conto do Graal") do trovador francês Chrétien de Troyes, do século XII. 
Querido irmão, se precisares lutar contra um cavaleiro, lembra-te do que vou dizer: se és tu quem ergue a cabeça [...] e se ele se vê forçado a pedir piedade, não o mates estupidamente, mas concede-lhe a misericórdia. Por outro lado, não sejas nem muito tagarela nem muito curioso [...] Aquele que fala demais comete um pecado; previna-te, pois; E se encontrares uma dama ou uma donzela em apuros, eu te imploro: faze o que estiver ao teu alcance para lhe prestar socorro. Termino com um conselho que não convém, sobretudo, desdenhar: entra seguidamente num mosteiro, e reza ao Criador de todas as coisas, para que Ele tenha piedade da tua alma e que nesta vida terrena te proteja enquanto cristão (PASTOREAU, 1989, p. 47).

Nesta mesma linha de raciocínio, Georges Duby resgata um documento do século XI, no qual o bispo de Beauvais, em 1024 ameaçou um castigo especial para todos os cavaleiros de sua diocese, caso estes atacassem mulheres que viajassem desacompanhadas de seus maridos, e de igual maneira, viúvas e freiras (DUBY, 1988, p. 67). FLORI acrescenta que o cavaleiro tinha, por dever de juramento, a obrigação de "não atacar, roubar ou extorquir os que não podem se defender: eclesiásticos, mulheres nobres não acompanhadas, camponeses e camponesas, pobres e desprotegidos em geral" (FLORI, 2002, p. 194). O mesmo FLORI acrescenta que o código de ética da cavalaria envolvia

O culto da coragem e do heroísmo, respeito ao código deontológico que poupa, por interesse ou por ideal, o homem desarmado ou caído por terra; respeito à palavra dada; zelo pela reputação, ampliada pela bravura de uns e pela generosidade de outros (FLORI, 2002, p. 196).

Não é de se admirar que a cavalaria tenha assumido um caráter mitológico, fazendo parte do imaginário popular, não apenas no próprio período medieval, mas até hoje. A expressão máxima 
deste caráter mitológico da cavalaria encontra-se no tema dos Le Neuf Preux ("Os nove bravos" ou "valentes"). Na tradição inglesa eles são chamados de The Nine Worthies, "Os nove dignos". Estes nove heróis, míticos ou reais, estão agrupados em três grupos de três: três judeus, três pagãos e três cristãos. FLORI explica:

Em meados do século XIII o tema dos "Nove Bravos" faculta a elaboração de uma espécie de história santa da cavalaria, que, através da antiguidade e de seus modelos (Heitor ${ }^{22}$, Alexandre ${ }^{23}$, Cesar $\left.{ }^{24}\right)$, liga os heróis da cavalaria cristã (Artur ${ }^{25}$, Carlos Magno ${ }^{26}$ e Godofredo de Bulhão ${ }^{27}$ ) aos da cavalaria bíblica (Josué, Davi e Judas Macabeu ${ }^{28}$ ) (FLORI, 2002, p. 197).

O imaginário dos Nove Bravos une a antiguidade clássica, a

22. Na llíada de Homero, Heitor é um príncipe de Troia, responsável por abater mais adversários que o próprio Aquiles, famoso por sua pele invulnerável.

23. Alexandre da Macedônia (356-323 a. C.), conhecido como Alexandre Magno ou Alexandre o Grande, conquistador de um dos maiores impérios da história, que ia da Grécia à Índia, passando pelo Egito. Morreu sem ter experimentado derrota em batalha. 24. Caio Júlio Cesar (100-44 a. C.), líder político e militar romano, considerado um dos maiores líderes militares da história.

25. Curioso que o legendário Rei Artur tenha sido escolhido para o rol dos Nove Bravos, pois, se houve um líder por nome Artur nas Ilhas Britânicas depois da saída dos romanos que conseguiu unificar todas as tribos em um só reinado, tal líder dificilmente seria cristão. Artur é um dos principais nomes da chamada Matéria da Bretanha, conjunto de relatos a respeito da história das Ilhas Britânicas. É muito difícil, talvez impossível, saber o que de fato aconteceu em sua trajetória, posto que as narrativas a seu respeito estão mescladas com muitos elementos lendários ou, no mínimo, hiperbolizados.

26. Carlos Magno - Charlemagne - rei dos francos, depois dos lombardos, coroado pelo Papa Leão III como imperador do Sacro Império Romano Germânico na noite de Natal do ano 800 . Foi o responsável pela cristianização forçada dos saxões, atitude não condizente com o ideal de nobreza de caráter que, em tese, se esperava de um cavaleiro cristão. 27. Godofredo de Bulhão (1058?1060-1100), líder da Primeira Cruzada, por ter conquistado Jerusalém, passou para a história como herói. Cronistas medievais descrevem-no como sendo de estatura elevada, coração nobre, parecendo-se mais com um monge do que com um cavaleiro: Godfrey of Bouillon. The Catholic Encyclopedia. New Advent. Disponível em < http://www.newadvent.org/cathen/06624b.htm > Acesso: 5 dez 17.

28. Os relatos da Tanach, a Bíblia Hebraica, apontam Josué e Davi como guerreiros bem sucedidos em todos as lutas que travaram, não sabendo o que significa derrota em campo de batalha. O mesmo é dito a respeito de Judas Macabeu, no texto grego da Septuaginta. A respeito de Davi, por exemplo, após apresentar uma sequência de vitórias sobre vários inimigos, o narrador insere sua conclusão teológica: "o Senhor dava vitórias a Davi por onde quer que ele ia" (2 Sm 8.14). 
herança judaica e a tradição cristã em torno de um mesmo ideal do cavaleiro perfeito, de excelência, nobreza e virtude, no combate e na vida.

Quanto ao ideal do cavaleiro, mas mais especificamente o cavaleiro cristão, o crítico literário e teólogo cristão britânico C. S. Lewis (1898-1963) apresenta uma contribuição que merece ser considerada. Lewis não esconde seu entusiasmo pela cavalaria, que considerava uma grande ideia cristã: o cavaleiro é o cristão devoto que sabe lutar, e usa suas habilidades em combate para proteger os vulneráveis, que de outra forma estariam indefesos diante de ataques de agressores diversos ${ }^{29}$. Portanto, não é surpresa que suas conhecidas Crônicas de Nárnia sejam apresentadas em uma estética medieval: os irmãos Peter (Pedro) e Edmundo (Edmund) Pevensie são sagrados reis e cavaleiros de Nárnia pelo próprio Aslan, o leão falante que é soberano supremo de toda aquela dimensão, uma muito clara alegoria de Jesus Cristo. Em Príncipe Caspian, A viagem do Peregrino do Alvorada e A última batalha aparece o personagem Ripchip, um rato falante que é apresentado como o cavaleiro perfeito: valente, destemido, nobre de caráter, sempre preocupado com a honra, leal à palavra empenhada até às últimas consequências. Ripchip é um cavaleiro idealizado, pois só tem virtudes. Todavia, esta idealização ilustra o conceito elevado de cavalaria abraçado por Lewis.

A compreensão lewisiana de cavalaria, sugerida nas Crônicas de Nárnia, aparece explícita em The Necessity of Chivalry, um texto pouco divulgado que é parte da coletânea Present Concerns, publicação póstuma, reunindo artigos de Lewis publicados em jor-

29. Lewis era medievalista, e lecionou Literatura Renascentista e Medieval nas universidades de Oxford (1925-1954) e Cambridge (1954-1963). Logo, tinha bastante conhecimento de fontes primárias medievais sobre a cavalaria. 
nais ingleses por muitos anos. No texto em questão, Lewis cita Le Morte Darthur, de Thomas Mallory, de 1485, no qual é dito a respeito de Lancelote, tido como o maior dos cavaleiros do Ciclo Arturiano da já mencionada Matéria da Bretanha: "Tu foste o homem mais meigo que já tomou uma refeição em um salão na presença senhoras; e tu foste o cavaleiro mais implacável contra teus inimigos mortais" (LEWIS, 1986, p. 13, tradução nossa). Lewis comenta sobre o ideal medieval do cavaleiro perfeito:

A coisa importante a respeito deste ideal evidentemente é a exigência dupla que este faz à natureza humana. $\mathrm{O}$ cavaleiro é um homem de sangue e ferro, um homem acostumado a ver rostos esmagados e os tocos esfarrapados de membros decepados; mas ele também é recatado, quase uma dama, um homem gentil, modesto, discreto. Ele não é um meio-termo feliz entre ferocidade e meiguice; ele é feroz à terceira potência, e meigo à terceira potência. Quando Lancelote soube que disseram que ele era o melhor cavaleiro do mundo, ele chorou como se fosse uma criança que tivesse levado uma coça (LEWIS, 1986, p. 13).

Prosseguindo em sua exposição, Lewis comenta sobre o paradoxo contido no ideal do cavaleiro medieval: "O ideal medieval reuniu duas coisas que não têm tendência natural para gravitarem uma ao lado da outra. $E$ isto pela seguinte razão: este ideal ensina a humildade e paciência ao grande guerreiro" (LEWIS, 1986, p. 14). Lewis sabia que ideal tão nobre só seria alcançado através de esforço e disciplina:

Em suma, ainda há vida na tradição que a Idade Média inaugurou. Mas a manutenção desta vida depende, em parte, de saber que o caráter cavaleiresco é arte, não natureza, algo que precisa ser conquistado, não algo que se espera que aconteça (LEWIS, 1986, p. 15). 


\section{Considerações teóricas -}

é possível ler HQs a partir de uma perspectiva teológica?

Tendo apresentado alguns aspectos sobre a religião em geral em algumas HQs, e tendo apresentado o ideal medieval do cavaleiro como um servo de Deus, é necessário tratar da questão quanto à base teórica para o diálogo entre HQs e teologia. É possível ler HQs a partir de uma perspectiva teológica?

Neste artigo será defendida a tese da possibilidade de leitura de HQs em geral, e, em particular, as do Demolidor na fase posterior a 1986, a partir de um prisma teológico. De que maneira? Leituras teológicas estariam na intentio operis e, antes ainda, na intentio auctoris, das quais fala Umberto Eco? Quanto a isto, o intelectual italiano afirmou:

[...] o debate clássico articulava-se, antes de mais nada, em torno da oposição entre estes dois programas: (a) deve-se buscar no texto aquilo que o autor queria dizer; (b) deve-se buscar no texto aquilo que o ele diz, independentemente das intenções do autor. Só com a aceitação da segunda ponta da oposição é que se poderia, em seguida, articular a oposição entre: (b1) é preciso buscar no texto aquilo que ele diz relativamente à sua própria coerência contextual e à situação dos sistemas de significação em que se respalda; (b2) é preciso buscar no texto aquilo que o destinatário aí encontra relativamente a seus próprios sistemas de significação e/ ou relativamente a seus próprios desejos, pulsões, arbítrios (ECO, 2004, p. 6-7).

Voltando à questão apresentada no parágrafo anterior: se HQs forem lidas sem as pressuposições da hermenêutica romântica alemã, que pretendia descobrir qual teria sido a intenção do autor de um dado texto, sim. Neste sentido, as contribuições de Paul Ricoeur podem ser particularmente úteis. Ricoeur contesta a proposta de hermenêutica romântica de Schleiermacher 
quando afirma:

O problema hermenêutico foi colocado, em primeiro lugar, nos limites da exegese, vale dizer, no contexto de uma disciplina que se propõe a compreender um texto, a compreendê-lo a partir de sua intenção, baseando-se no fundamento daquilo que ele pretende dizer (RICOEUR, 1978, p. 7).

Em contraste com a hermenêutica romântica alemã, que defendia uma simetria absoluta entre o sentido semântico de um texto e a intenção de seu autor, Ricoeur defende a ideia da autonomia do texto: "Faz parte da significação de um texto estar aberto a um número indefinido de leitores e, por conseguinte, de interpretações. Esta oportunidade de múltiplas leituras é a contrapartida dialética da autonomia semântica do texto" (RICOEUR, 1973, p. 43). Nesta mesma linha de raciocínio Ricoeur afirma, talvez de maneira radical, que considerando-se a autonomia do texto a intenção do seu autor se torna secundária no processo de interpretação (RICOEUR, 1983, p. 53). Em outras palavras: há no texto literário um "excesso de sentido" (RICOEUR, 1973, p. 57), e ler um texto - uma HQ no caso - a partir de uma ótica teológica talvez não muito evidente no nível semântico não se constitui propriamente em Entstellung, "adulteração" ou "deturpação" do sentido deste texto $^{30}$. O excesso de sentido provocará conflito de interpretações. Mas "no conflito das interpretações a equivocidade pode redundar, contudo, em acréscimos de sentido somente no dinamismo do conflito das interpretações se mostra o mundo do humano no seu modo de ser como linguagem" (CANTARELA, 2002, p. 31).

30. Ricoeur comenta sobre a ideia de Entstellung ao dialogar com a psicanálise de Freud no processo de interpretação literária, especificamente quando fala sobre o "movimento não semântico de um símbolo" (RICOEUR, 1973, p. 69-73). 


\section{Demolidor como um cavaleiro cristão}

As mencionadas fontes da historiografia francesa e as considerações de Lewis a respeito dos ideais nobres da cavalaria medieval, a intuição de Morris a respeito do Demolidor e a ideia ricoeuriana da autonomia do texto e da construção do seu sentido pelo leitor (ideia que de certa forma, é paralela à ideia da intentio lectoris exposta por Eco) auxiliam a entender a hipótese do presente artigo, a saber, apresentar o "Homem sem medo" como representação contemporânea do cavaleiro medieval.

Mas é preciso pensar nas diferenças - óbvias, mas que não podem ser esquecidas ou ignoradas - entre os relatos históricos referentes à cavalaria medieval e a narrativa (ou narrativas) do Demolidor. Pois certamente não há um paralelo exato e absoluto ponto a ponto entre o cavaleiro medieval e o Demolidor. Em outras palavras: não há como fazer uma tabela com duas colunas e algumas linhas, sendo uma com características do cavaleiro medieval, e na outra, características do Demolidor, havendo equivalência entre ambas ponto a ponto. Um paralelo assim seria óbvio demais. Neste sentido, uma das diferenças principais é que o Demolidor não faz parte de uma ordem religiosa cujos integrantes são treinados em combate corporal para proteger os indefesos ${ }^{31}$. Logo, ele não passou por uma cerimônia especial de "ordenação". Seguindo

31. Curiosamente há na DC, a rival e grande competidora da Marvel pela primazia e na luta para alcançar o primeiro posto no gosto do público e em vendas de produtos licenciados, um personagem que se enquadraria nesta descrição, isto é, um herói que é membro de uma ordem de orientação cristã que vem desde a Idade Média, cujos integrantes são treinados em combate corporal para enfrentar o mal e a injustiça: Jean-Paul Valley, membro da Sagrada Ordem de São Dumas, cuja missão é exatamente punir os criminosos. Jean-Paul Valley, conhecido como Azrael - o nome do anjo da morte nos folclores judaico e islâmico. Em um conhecido arco do Batman, "A queda do morcego", Bruce Wayne tem sua coluna partida por um supervilão, o Bane, e é temporariamente substituído por Jean-Paul Valley. 
esta mesma linha de raciocínio, em decorrência da diferença anterior: o Demolidor não atua obedecendo a ordens de uma autoridade religiosa, como atuavam, por exemplo, os Cavaleiros Templários, submissos ao Papa. Por isso também como os Templários eram monges, tinham que assumir os votos de pobreza, castidade e obediência. O Demolidor é um cristão católico "leigo", por assim dizer, e não tomou nenhum dos três votos clássicos.

Sendo assim, em que sentido se pode dizer que o Demolidor é uma representação atual do cavaleiro medieval? Suas narrativas deixam muito claro o seguinte: seja como advogado durante o dia, ou como um mascarado combatente do crime durante a noite, o que Matt Murdock/Demolidor deseja é fazer justiça em prol dos que dela precisa. Foi exatamente por isso que o jovem Murdock decidiu por estudar Direito, e não Medicina, como seu pai queria (CRILLEY, 2017, p. 193). Matt Murdock entendeu como advogado que poderia fazer muito mais pelos injustiçados que como médico.

Não será demais repetir que o elemento cristão na configuração do Demolidor aparece a partir da mais de uma vez mencionada recriação do personagem feita por Frank Miller, em meados dos anos de 1980. Miller criou vários personagens coadjuvantes na trama do Demolidor, o que ajudou a dar mais profundidade e densidade dramática à narrativa do herói. Um deles é Margaret Grace Murdock, a mãe de Matt. Conhecida pelo apelido de Maggie, a mãe de Matt abandona o marido e o filho quando este ainda era um menino. Este só se reencontrará com sua mãe anos depois, já adulto, e descobrirá que neste intervalo ela se tornou uma freira. No arco Demolidor: diabo da guarda ${ }^{32}$, de 1999, Maggie diz a seu

32. Para uma análise do conteúdo de Demolidor: diabo da guarda, consultar CALDAS, 2018, p. 211-222. 
filho: "Eu sei que seu pai o educou na fé. Sei também, depois de ler a respeito de suas duas vidas todos esses anos, que você trabalha pelos justos. Você é um anjo, Matthew - não um daqueles anjos das hostes celestiais, mas mesmo assim um servo de Deus" (apud MORRIS, 2009, p. 56). Neste mesmo arco, que tem a temática religiosa como elemento central na narrativa, depois de passar por uma crise de fé, e de superá-la, no último quadro, no confessionário, Matt Murdock ouve um pedido de socorro de uma criança em situação de perigo. Ele imediatamente sai da igreja, no meio da confissão, e quando o padre pergunta aonde ele vai, sua resposta é "Fazer a obra do Senhor, padre. Fazer a obra do Senhor".

Resumindo: todo herói, ou super herói, tem como meta a luta pelo bem e pela justiça, e o combate ao mal e à injustiça. Mas na maioria dos casos suas narrativas os apresentam envolvidos nesta luta a partir de uma motivação humanista, secularizada, sem qualquer vinculação religiosa. Em contraste, o Demolidor é apresentado como sendo um campeão do combate ao mal a partir de uma motivação cristã. Suas habilidades são entendidas como dons de Deus, e não como mero resultado de um acidente ou fatalidade do destino. Assim, ao assumir o uniforme do Demolidor, Matt Murdock entende que está exercendo um "ministério", não ordenado, não vinculado a uma instituição eclesiástica, mas que nem por isso deixa de ser um serviço cristão ao próximo.

\section{Concluindo...}

A tese principal deste artigo é a compreensão do Demolidor como um cavaleiro cristão do tempo atual. Assim como os cavaleiros da Idade Média, o Demolidor entende que ao usar suas habilidades e destrezas super desenvolvidas para combater o mal, ele 
está servindo a Deus. Nas palavras de C. S. Lewis,

Meu tema é a cavalaria. Tentei demonstrar que esta antiga tradição é prática e vital. O ideal incorporado em Lancelote é "escapismo" em uma maneira jamais sonhada pelos que usam a palavra; este ideal oferece a única fuga possível de um mundo dividido entre lobos que não entendem, e ovelhas que não conseguem defender as coisas que tornam a vida desejável (LEWIS, 1986, p. 16).

Estas palavras foram escritas anos antes da criação do Demolidor por Stan Lee, e, mais ainda, décadas antes da reconfiguração do personagem feita por Frank Miller, que o transforma em um herói cristão. Tom Morris apresenta um resumo do Demolidor como um herói cristão:

Não parece exagero somar a influência que Deus tem na vida de Matt e os esforços de Matt (sic) para aplicar a justiça divina, concluindo que ele ama a Deus, mesmo que se preocupe com sua existência. Isso não é pouco para um homem cego, profundamente perturbado, que é um intelectual, advogado e um cidadão decente, porém vivendo em meio a todo o mundo de crime, ódio e abuso da Cozinha do Inferno. O Demolidor também tenta amar o próximo como a si mesmo. Com certeza, ele faz mais pelos outros que a maioria de seus próximos faria. Ele arrisca a vida quase todas as noites para eu os outros tenham uma certa (sic) segurança e proteção. Ele faz coisas boas para 6os outros sempre que possível e de diversas maneiras. É um bom amigo. Tem aspirações nobres. Ele reza. Ele defende os fracos. E sente que vive sob a tutela de um ser que ele não vê nem ouve, mesmo com seus sentidos superapurados. Ele parece ser um católico mito especial, com uma medida de real fé espiritual e suficiente honestidade para reconhecer as próprias dúvidas, e ao mesmo tempo suficiente persistência para nunca permitir que essas dúvidas dominem sua vida (MORRIS, 2009, p. 68-69).

A interface acadêmica entre teologia/estudos de religião e cultura nerd inicia sua jornada no Brasil na direção do reconhecimen- 
to de sua cidadania acadêmica. O presente artigo pretende ser um passo desta jornada. Espera-se que outros trabalhos nesta linha venham a ser produzidos, consolidando esta (por enquanto) nova fronteira de investigação acadêmica na teologia e nos estudos de religião.

\section{Referências}

CALDAS FILHO, Carlos Ribeiro. Religião e HQs: análise de Demolidor: diabo da guarda, de Kevin Smith e Joe Quesada. Numen. V. 21, N. 1, p. 211-222, 2018.

CANTARELA, Antonio Geraldo. O universo da recepção em Iracema e em Sansão e Dalila. Dissertação. Mestrado em Letras. Belo Horizonte: Pontifícia Universidade Católica de Minas Gerais.

THE CATHOLIC ENCYCLOPEDIA. New Advent. Godfrey of Bouillon. Disponível em < http://www.newadvent.org/cathen/06624b.htm > Acesso em: 13 dez. 2017

CRILLEY, Paul. Demolidor, o homem sem medo. São Paulo: Novo Século, 2017

DAREDEVIL. Grand Comics Database. Disponível em <https://www.comics.org/ issue/18338/>

DUBY, Georges. O cavaleiro, o padre e a mulher. Lisboa: Publicações Dom Quixote, 1988

DUBY, Georges. A sociedade cavalheiresca. Lisboa: Teorema, 1989

ECO, Umberto. Os limites da interpretação. 2a edição. São Paulo: Perspectiva, 2004

FLORI, Jean. "Cavalaria”. In LE GOFF, Jacques, SCHMITT, Jean-Claude. Dicionário temático do Ocidente medieval. Volume I. São Paulo: Imprensa Oficial do Estado. Bauru: EDUSC, 2002

GUEDES, Roberto. Jack Kirby, o criador de deuses. São Paulo: Noir, 2017

GUERRIERO, Silas. STERN, Fábio Leandro. Espiritualidade e magia nas histórias em quadrinhos da Marvel. Caminhos. V. 17, N. 1, 2019

LEWIS, C. S. "The Necessity of Chivalry". In Present Concerns. A compelling collection of timely journalistic essays. Orlando: Harcourt, 1986

MARVEL 616. Charlie Cox fala sobre o uniforme do Demolidor. Disponível em http://www.marvel616.com/2015/01/charlie-cox-fala-sobre-o-uniforme-do.html Acesso em: 02 mar. 2018 
MELLO, José Roberto. O cotidiano no imaginário medieval. São Paulo: Contexto, 1992

MORRIS, Tom. Deus, o diabo e Matt Murdock. In MORRIS, Matt e MORRIS, Tom (Orgs.). Super-heróis e a filosofia. Verdade, justiça e o caminho socrático. São Paulo: Madras, 2009

PASSOS, Leonardo Porto. Review-HQ: Demolidor - Diabo da Guarda. HQ Maniacs. Disponível em <http://hqmaniacs.uol.com.br/principal.asp?acao=materias\&cod materia $=1074>$ Acesso em: 02 mar. 2018

PASTOREAU, Michel. No tempo dos Cavaleiros da Távola Redonda. Coleção A vida cotidiana. São Paulo: Brasiliense, 1989

RICOEUR, Paul. Teoria da interpretação. O discurso e o excesso de significação. Lisboa: Edições 70, 1973

RICOEUR, Paul. O conflito das interpretações. Ensaios de hermenêutica. Rio de Janeiro: Imago, 1978

RICOEUR, Paul. Interpretação e ideologias. 2a edição. Rio de Janeiro: Francisco Alves, 1983

SINGER, Isaac Bashevis. O Golem. São Paulo: Perspectiva, 2015

WIESEL, Elie. O Golem. Rio de Janeiro: Imago, 1986 